\title{
An IMMERSE-Style Course Brings a Research Experience to Students and Faculty
}

Ellen Veomett

A common challenge that new faculty face at primarily teaching institutions is finding the time and energy for research. With all of the day-to-day duties of a large course load, new course preps, committee work, and service to the college and community, how does a young faculty member keep her research program alive? More than that, recently there has been a (very positive, in my opinion) push towards including undergraduate students in research projects, as well as a (very positive again) push towards "bridging the gap" between an undergraduate and graduate degree.

I recently had the pleasure of participating in a summer program that allowed me to address these issues. While not every young faculty member can participate in such a program, every young faculty member can do what I did the following year: teach a similar course at her home institution. This article is intended to explain the course, as well as how it can be successfully adapted to a "regular" semester-length or quarter-length course.

Ellen Veomett is assistant professor of mathematics at Saint Mary's College of California. Her email address is erv2@stmarys-ca.edu.

The author was supported for eight weeks during the summer of 2010 through the University of Nebraska-Lincoln's Mentoring through Critical Transition Points grant DMS0838463 from the National Science Foundation.

DOI: http://dx.doi.org/10.1090/noti890
The IMMERSE-Style Course

This "miracle" course which achieves so much has at its core a single goal: getting the students to read a research paper. The instructor teaches the students any material they need to know in advance of reading the paper, and then they read the paper.

The first time I taught such a course was during the summer IMMERSE program at the University of Nebraska (IMMERSE stands for Intensive Mathematics: a Mentoring, Education and Research Summer Experience). For about six weeks I met with twenty students three hours a day, four days a week. The students were all staying on campus together in dorms, all entering Ph.D. programs in the fall, and all being paid for their time. They were also taking two courses of this type. Thus they were spending twenty-four hours a week in class learning to read two research papers (one falling under the analysis umbrella, the other algebra).

The second time I taught the course was at $\mathrm{Cal}$ State University East Bay in Hayward, CA. This was a regular course, meeting twice a week for two hours over a 10-week quarter. Cal State East Bay is a commuter campus with an extremely diverse student background. All eleven of the students in my class were Masters students; to my knowledge, three of them were planning on eventually finishing a Ph.D. program. These students were all taking other courses, most were also working, and most were taking comprehensive exams at the end of the quarter. 
Even with the great differences in situation and population, both of these groups of students thrived and had a great appreciation for the course. Of course, a certain amount of interest and motivation is required of any student wishing to complete such a course. So long as participation in a course such as this is not compulsory, I suspect that any student deciding to "sign on" already has the requisite drive.

\section{The Benefits of an IMMERSE-Style Course}

The greatest benefit for the students is the experience of the course. The students have a chance to struggle with topics that are on the edge of their mathematical understanding. With the right kind of nudging, they will be able to, on their own, piece together new knowledge and master new results. This experience of a slow struggle eventually ending in a deep understanding is extremely empowering. The more chances students have to encounter great reward for great struggle, the more students will be willing to undergo that great struggle in the future.

Students will additionally benefit from the material they learn. When reading a modern research paper, students have the opportunity to learn new topics and ideas that they would not normally be exposed to in the typical studies for an undergraduate or master's degree. While areas of mathematics tend to be artificially separated for the purposes of teaching, an IMMERSE-style course helps students see how various types of mathematics interact in research. The students also leave such a course having a much better understanding of mathematics research, as well as the typical structure and design of a research paper.

Comments that students made anonymously in both of the courses that I taught suggest that the above benefits were indeed achieved:

With the topics introduced by the professor, and the given assignments, it was challenging enough to cause occasional despair but attainable enough to have some highs induced by new understanding. . . . For me the course was a revelation. You mean I can understand an advanced research paper? You've got to be kidding me!!! . . . I learned that with the right amount of patience, desire and resources it is possible. - Cal State student

At times I felt that the material was really difficult, but that made it more satisfying when I finally understood it. I'm now looking forward to taking analysis in grad school. -IMMERSE student
What was probably most beneficial and most enjoyable was seeing a number of different areas of math come together for use in interesting ways. In most classes topics are compartmentalized, however the paper we studied in particular was really a cohesion of some usually very different topics. - Cal State student

I would certainly say I've increased my analysis skills and have especially learned a lot about how to get through research papers. -IMMERSE student

Finally, the instructor herself receives many benefits by teaching a course focused on reading a research paper. She has the time and incentive to read a very important paper that will help her in her own research. She is renewed by the chance to think about recent mathematical discoveries. And, of course, she also has the chance to experience that great "aha moment" when she successfully reads through and understands something complicated. Even designing a course that helps to make those "aha moments" more accessible to students is itself a rewarding task.

\section{How-To}

Now that I've thoroughly convinced you that you'd like to teach such a course, I'll let you know my suggestions on how to do so based on my experiences. The first step is to choose a good paper. The paper should be on the shorter side, probably not more than $10-15$ pages. I chose a paper by Bourgain [1] that was seven pages long (albeit a very dense seven pages). The paper should be something which greatly interests you and about which you have at least a little knowledge. That way, you will be happily willing to put in the hard work required to design the course. Finally, the paper should be important. By important, I mean that it should be relatively new and highly referenced. You and your students will be doing a lot of work with this paper; why not choose something that has a good chance of being useful in your future research careers? In my search for the right paper, I heavily used the "citations" search option on MathSciNet as a way of finding those "important" papers.

Once the paper is chosen, the course is designed around it. After a first cursory reading, you can see what topics the students will need to know before first encountering the paper. If you don't know the students who will be taking the course, it may be helpful to send them a survey in advance in order to better appreciate the variety of the students' backgrounds. Both times I taught this course, there were two relatively distinct stages: the lecture stage and the reading stage. 


\section{The Lecture Stage}

The lecture stage is the time when the students are learning the material that they need to know before reading the paper. Both times I taught the course, this lasted the first half of the term (three weeks at IMMERSE, five weeks at Cal State). For me, the lecture stage was similar to a typical course in that I was lecturing each time we met, and the students were regularly doing homework on the topics from lecture. The homework problems were generally intended to help ingrain understanding and familiarity with the topics, although sometimes I could include things that came directly from the paper. For example, early in the course we were learning about metric spaces, and I assigned the following problem, which appeared as a statement without proof in the paper:

Let $X$ be a metric space, let $A \subset X$ and let $x, y \in X$. Define

$$
d(x, A)=\inf \{d(x, a): a \in A\} .
$$

Prove that

$$
|d(x, A)-d(y, A)| \leq d(x, y) .
$$

As we were nearing the end of the lecture stage, I assigned the following:

Let $\left(X, d_{X}\right)$ be a metric space and suppose that $X$ has finitely many points in it. Say that $X$ has $n$ points in it so that we can label $X=\left\{x_{1}, x_{2}, x_{3}, \ldots, x_{n}\right\}$. Consider the map

$$
F:\left(X, d_{X}\right) \rightarrow\left(\mathbb{R}^{n},\|\cdot\|_{\infty}\right)
$$

defined by

$$
\begin{aligned}
& F\left(x_{i}\right) \\
& =\left(d_{X}\left(x_{1}, x_{i}\right), d_{X}\left(x_{2}, x_{i}\right), d_{X}\left(x_{3}, x_{i}\right), \ldots, d_{X}\left(x_{n}, x_{i}\right)\right) \\
& \quad \text { for each } i=1,2,3, \ldots, n .
\end{aligned}
$$

(1) For $x_{1}, x_{2} \in X$, calculate

$$
\left\|F\left(x_{1}\right)-F\left(x_{2}\right)\right\|_{\infty} .
$$

(2) Prove that

$$
|| F||_{\text {Lip }}|| F^{-1}||_{\text {Lip }}=1 .
$$

The second of the two parts appeared as a statement without proof in the paper.

The main way in which the lecture stage differed from a typical lecture course was that it included student presentations. These were short presentations of homework problems given by students. When I taught this course through the IMMERSE program, the students knew perhaps the day of (or the day before) that they would be presenting a particular problem. At Cal State East Bay, the homework that I handed out had a list of problems to be handed in and another list of problems to be presented. The students volunteered to present a problem the day it was listed as its presentation day.
There were several reasons I included student presentations. The main reason was that I wanted the students to begin feeling comfortable with feeling uncomfortable. Reading a research paper is often frustrating and confusing, and those uncomfortable feelings will often discourage someone who is not used to experiencing them. I believe that the act of explaining something in front of the class gave my students a chance to become accustomed to feeling "out of their element", as well as the confidence to believe that they belonged in the class. It also helped them to feel camaraderie with their classmates (everyone had to present), which was important for the reading stage of the course.

\section{The Reading Stage}

Once the students know enough of the background mathematics, the reading stage begins. This stage includes three main parts:

(1) Prepaper Problems,

(2) Reading,

(3) Clarification/Enrichment Presentations,

all of which occur throughout the reading stage.

Prepaper problems replace regular homework problems during this time of the course. They are created as follows: when reading through the paper, you will see places (maybe many places) where the reader will need to "fill in the gaps". Perhaps this is simply using a well-known fact, or perhaps it is fleshing out an outlined argument, or perhaps it is completing a hidden computation. Whatever it may be, a prepaper problem is a homework problem that mimics what the students will need to do when they come to that place in the paper. Since the problem mimics the elaboration that must be made in order to understand the paper (but isn't the precise argument), the students are not being spoon-fed, nor do they feel as though they are. Rather, having seen a similar argument previously, when they encounter it in the paper they will have some familiarity with how to proceed.

Here is an example of a prepaper problem:

Recall from class that if $F:\left(X,\|\cdot\|_{X}\right) \rightarrow$ $\left(Y,\|\cdot\|_{Y}\right)$ is linear, then

$$
\|F\|_{\text {Lip }}=\sup \left\{\|F(x)\|: x \in X,\|x\|_{X}=1\right\} .
$$

(1) Consider the map $f:\left(\mathbb{R}^{2},\|\cdot\|_{\infty}\right) \rightarrow$ $\left(\mathbb{R}^{2},\|\cdot\|_{1}\right)$ defined by

$$
f((x, y))=(2 x,-y) .
$$

(a) Convince yourself that $f$ is linear.

(b) What is $\|f\|_{\text {Lip? }}$ ? 
(2) Consider the map $g:\left(\mathbb{R}^{n},\|\cdot\|_{\infty}\right) \rightarrow$ $\left(\mathbb{R}^{n},\|\cdot\|_{1}\right)$ defined by

$$
g\left(x_{1}, x_{2}, x_{3}, \ldots, x_{n}\right)=\left(x_{1}, 2 x_{2}, 3 x_{3}, \ldots, n x_{n}\right) .
$$

(a) Convince yourself that $g$ is linear.

(b) What is ||$g||_{\text {Lip }}$ ?

This problem was intended to prepare the students for the first section of Bourgain's paper [1], where he defines a function that is essentially from $\left(\mathbb{R}^{n},\|\cdot\|_{\infty}\right)$ to $\left(\mathbb{R}^{n},\|\cdot\|_{1}\right)$ and states an upper bound on the Lipschitz norm $\|\cdot\|_{\text {Lip }}$ of that function. This function, like the two functions $f$ and $g$ above, is a diagonal linear function. The description of the function is relatively dense, and so the students must go through some effort to simply understand the function, and then they must go through some work to calculate an upper bound on the Lipschitz norm. Having calculated the Lipschitz norm of a diagonal linear function beforehand, they were able to get through that part of the paper without either getting bogged down with frustration or feeling like the paper had been explained to them in advance.

Another straightforward place to use a prepaper problem is in the case of a computation. For example, Bourgain [1] states that

$$
\sum_{j=1}^{n-1}\left(\begin{array}{l}
n \\
j
\end{array}\right)\left(1-\frac{M}{n}\right)^{j(n-j)}<\frac{1}{50}
$$

if $M>C \log (n)$. Since this statement is nonobvious upon inspection, I broke the computation down into several chewable pieces. Specifically, I first asked students to show

$$
(1-x)^{p} \leq e^{-x p} \text { for all } x \in(0,1), p>0,
$$

giving a hint for an argument using only concepts from differential calculus. Then they were asked to split the sum into two pieces:

(1) (a) Argue that

$$
\sum_{i=\frac{2}{5} n}^{\frac{3}{5} n}\left(\begin{array}{l}
n \\
i
\end{array}\right) \leq 2^{n}
$$

(b) Let $C>0$ and assume that $C \frac{\log (n)}{n}<1$. Use your above estimate to give an upper bound for

$$
\sum_{i=\frac{2}{5} n}^{\frac{3}{5} n}\left(\begin{array}{l}
n \\
i
\end{array}\right)\left(1-C \frac{\log (n)}{n}\right)^{i(n-i)} .
$$

(Hint: Remember that $(1-x)^{p} \leq$ $e^{-x p}$ for all $x \in(0,1), p>0$.) Show that, for example, if $n \geq 30$ and $C \geq 8$, then the above sum is no more than $\frac{1}{100}$.
(2) Suppose $C \frac{\log (n)}{n}<1$ and consider the sum

$$
\begin{aligned}
& \sum_{i=1}^{2 n / 5}\left(\begin{array}{c}
n \\
i
\end{array}\right)\left(1-C \frac{\log (n)}{n}\right)^{i(n-i)} \\
& +\sum_{i=3 n / 5}^{n-1}\left(\begin{array}{l}
n \\
i
\end{array}\right)\left(1-C \frac{\log (n)}{n}\right)^{i(n-i)} .
\end{aligned}
$$

(a) As $i$ increases from 1 to $2 n / 5$, show that the terms

$$
\left(\begin{array}{l}
n \\
i
\end{array}\right)\left(1-C \frac{\log (n)}{n}\right)^{i(n-i)}
$$

decrease by calculating the ratio of successive terms. Specifically, show that the $i$ th term divided by the $(i-1)$ th term is $<1$. (Hint: Remember that $(1-x)^{p} \leq$ $e^{-x p}$ for all $x \in(0,1), p>0$.)

(b) (i) Show that the $i$ th terms and the ( $n-$ i) th terms in the sum are the same.

(ii) Show that the sum is less than $\frac{1}{100}$ if, for example, $n \geq 30$ and $C \geq 8$.

This gave students much more direction in terms of how to argue a complicated inequality and in general made the process much less daunting while still in the end asking them to prove the inequality. When the students encountered the claimed inequality, they already knew how to prove it and thus could focus on the argument for how the equation $\sum_{j=1}^{n-1}\left(\begin{array}{l}n \\ j\end{array}\right)\left(1-\frac{M}{n}\right)^{j(n-j)}$ comes into play rather than getting entangled in the computation.

The reading stage of the course also includes, of course, reading. A good portion of this should happen in groups during class time. The students work through sections of the paper and discuss with each other how to get from one step to the next. Doing this in groups allows the students to keep each other motivated, and it helps them to work through the paper at the same pace. Doing this during class time allows you to answer their questions as they arise. It also allows you to listen in on the discussions and steer them in the right direction if a group starts veering away from helpful ideas. It is important to let the students struggle but not get stuck in a rut. I recommend assigning the groups that the students work in (so that they are balanced) but rotating groups every week or so (so that they can become reenergized by new reading partners).

Finally, the reading stage includes clarification and enrichment presentations. This may include a continuation of lectures on the topics that had been previously introduced, and it may include lectures on topics that help to orient the paper within a field of study. For example, I lectured on measure concentration and the F. John Ellipsoid. These topics were alluded to in the paper [1], 
and these lectures allowed the students to get a flavor of techniques and ideas used in metric geometry. Presentations should also be given to "wrap up" sections of the paper. This allows all of the students to both fully understand what they had discussed in their small groups as well as understand the context of the paper. During the IMMERSE course, I had students present sections of the paper, while I explained the general context and significance of the questions addressed in the paper. At Cal State East Bay, in the interest of saving time, I did all of the "wrap-up" presentations myself.

\section{Last Thoughts}

In an effort to help you as you plan a similar course, I have posted a few resources on my webpage: https://sites.google.com/a/stmarys-ca. edu/e11en-veomett/immerse-course-

resources

There you can find the schedule that I used when teaching the course at Cal State, as well as some sample lectures and assignments. These will give you an even more concrete idea of the implementation of an IMMERSE-style course.

While I do think that this kind of course can be held at any institution with a motivated faculty member and motivated students, there were some wonderful resources that I had the first time I taught this course through the IMMERSE program. First, I had a University of Nebraska faculty member (Jamie Radcliffe) who acted as my mentor. He gave feedback on the course design, shared his favorite examples so that I could include them in the course, and helped me to thrash out the complicated arguments in the paper. Second, I had the aid of three University of Nebraska graduate students (Joe Geisbauer, Lauren Keough, and Zahava Wilstein). These graduate students helped the IMMERSE students as they were doing group work, checked the IMMERSE students' written homework, and also read through my lecture notes and homework sets in advance, catching many errors and typos before they were a problem. Without all of this help, the course preparation would have been much more daunting, time-consuming, and lonely.

Similar resources may be available for you at your institution: perhaps you have a trusted colleague who you know would help you to bounce ideas around, and perhaps you have funding for student assistants. If not, the burden will be much more on you in terms of finding the time for all of the preparation involved and the motivation to craft a cohesive and thorough course. The results of the course are well worth it, though. You will be reinvigorated in your research, and the students will be exposed to new ideas and new ways of learning. Both you and your students will feel the satisfaction of receiving great reward for great struggle.

\section{Acknowledgments}

I would like to thank Joe Geisbauer, Lauren Keough, Zahava Wilstein, and in particular Jamie Radcliffe, whose help was invaluable in making the IMMERSE course a success. I would also like to thank the University of Nebraska for hosting the IMMERSE program, the NSF for supporting it (DMS-0838463), Tom Marley for directing it the summer of 2010, and Cal State East Bay for giving me the chance to teach the course again. Finally, I would like to thank my husband, Aaron, for his love, support, and advice.

\section{References}

1. J. BourgaIN, On Lipschitz embedding of finite metric spaces in Hilbert space, Israel J. Math. 52 (1-2):46-52, 1985. 